Belo Horizonte, v. 12, n. 2, p. 117-139, mai.-ago. 2020 - ISSN 1983-3652 DOI : $10.35699 / 1983-3652.2020 .24379$

\title{
A PESQUISA EM LINGUAGEM E TECNOLOGIA NO ENSINO DE INGLÊS NO NORDESTE DO BRASIL
}

\author{
RESEARCH ON LANGUAGE AND TECHNOLOGY IN THE ENGLISH LANGUAGE \\ TEACHING IN THE NORTHEAST OF BRAZIL
}

\author{
Rodrigo Camargo Aragão \\ Universidade Estadual de Santa Cruz, Brasil \\ aragaorc@gmail.com
}

\begin{abstract}
RESUMO: Neste artigo, apresentamos o estado da arte de pesquisas em linguagem e tecnologias no ensino de inglês a partir do mapeamento da região Nordeste do Brasil de 2013 a 2017. O período escolhido é justificado pela comparação com os resultados de um mapeamento com recorte temporal anterior (PAIVA, 2013). O estudo se embasa em pesquisa de estado da arte (FERREIRA, 2002) e procedimentos de análise de conteúdo (DÖRNIEY, 2007). Buscou-se estabelecer unidades e temas significativos do corpus, inicialmente, no banco de teses e dissertações da CAPES, e posteriormente, nos portais eletrônicos dos programas de Pós-graduação em Letras e Linguística. Os resultados indicam continuidades nas práticas metodológicas, mas também tendências inovadoras. Destaca-se a presença de estudos que avaliam políticas públicas de tecnologias, a produção textual multimodal, bem como a continuidade de desafios enfrentados por professores de inglês no uso de tecnologias.
\end{abstract}

PALAVRAS-CHAVE: Linguagem. Tecnologia. Ensino. Inglês.

ABSTRACT: This paper aims at presenting the state of the art of researches on language and technology in English Language Teaching based on research from graduate programs in the Northeast region of Brazil, from 2013 to 2017. We compared the results of this study with a previous state of the art by Paiva (2013). The study is based on research about the state of the art (FERREIRA, 2002) and qualitative research procedures of content analysis (DÖRNIEY, 2007). Common themes were organized from the collected corpus, initially, at the dissertations and thesis database of CAPES, and later, at the electronic websites of the Graduate Programs in Languages and Linguistics with results related to our research. Results indicate some continuities in methodological practices, but also innovative trends. Noteworthy are studies that evaluate public policies on educational technologies, multimodal text production, as well as the continuity of the challenges faced by English Language teachers in their use of technologies.

KEYWORDS: Language. Technology. Teaching. English.

\section{Introdução}

Nas Orientações Curriculares para o Ensino Médio - OCEM (BRASIL, 2006), bem como na Base Nacional Comum Curricular - BNCC (BRASIL, 2018), em que se inserem as orientações curriculares para os professores de língua estrangeira da Educação Básica, é notável a presença de conceitos associados a mudanças em curso em nossas 
sociedades tecnologicamente complexas. Essas mudanças têm sido objeto de uma série de estudos na Linguística Aplicada que tem se debruçado sobre o papel da tecnologia digital em práticas de linguagem. Este trabalho se insere no âmbito de um projeto maior intitulado "Lalintec: um ecossistema de produção e divulgação de pesquisas em linguagem e tecnologia"1. A partir de pesquisas realizadas pelo Laboratório de Linguagem e Tecnologia (http://www.letras.ufmg.br/lalintec/), temos aprofundado estudos sobre a temática da linguagem e tecnologia no ensino e na aprendizagem de língua inglesa (LI), em particular, sobre linguagem, tecnologia e inovação, de maneira mais ampla. Após identificarmos ausência de estudos que mapeiem o que tem sido produzido nas diversas regiões do País, parte do nosso projeto tem como uma de suas metas pesquisar como a temática das linguagens e tecnologias no ensino de inglês se encontra atualmente. A partir daí, com a socialização dos conhecimentos gerados, será possível, por exemplo, articular novas redes de pesquisa e retroalimentarmos disciplinas na graduação e pósgraduação.

Sabemos que as práticas sociais com linguagem e tecnologias pressionam por outras formas de ensinar e aprender, mas também proporcionam resistências nas atividades institucionais e nos letramentos. Ainda, conforme nos indica Paiva (2013), temos conhecimento sobre as dificuldades para acompanharmos a velocidade dessas inovações tecnológicas, tanto na pesquisa quanto em ações pedagógicas, o que justifica igualmente o aprofundamento de nosso conhecimento sobre o que tem sido produzido sobre o tema. Mais recentemente, nota-se uma rápida e crescente convergência de sistemas de informação e comunicação, antes presentes somente em computadores, mas agora convergentes em equipamentos móveis como tablets, mas, particularmente o smartphone. De fato, a convergência de tecnologias digitais diversas, integrando dispositivos que permitem a articulação de som, imagem e textos, tem impactado sobremaneira a área.

Assim, observamos o crescimento de pesquisas sendo desenvolvidas em temas como gêneros textuais em ambientes digitais, ensino/aprendizagem de línguas online e em ambientes virtuais de aprendizagem, sites de redes sociais, ensino de línguas mediado por dispositivos móveis, aspectos semióticos da interação humano-computador e formas variadas de apropriação tecnológica em contextos escolares, com impactos para 0 estudo e desenvolvimento de materiais didáticos de ensino de línguas.

Entretanto, ao realizar um estado da arte sobre a pesquisa em linguagem e tecnologias produzida de 2000 a 2012 na UFMG, Paiva (2013, p. 933) nos indica que a maioria das pesquisas está no campo do ensino de língua inglesa e língua portuguesa. Como resultado, a autora nos mostra como, por exemplo, ainda há poucas pesquisas sobre produção textual na Internet, seja escrita, oral ou multimodal. Conforme a autora argumenta, isso se apresenta, pois a esmagadora maioria das pesquisas trabalha com a habilidade de leitura na Internet ou mesmo comparando estratégias de leitura entre o ambiente digital e no suporte impresso. Ainda, foi identificado pela pesquisadora que até 2012 não havia estudos que se debruçassem sobre os elementos envolvidos na interação virtual e sobre a linguagem de sites de redes sociais, como o Facebook. Além disso, a pesquisadora identificou outras lacunas nas pesquisas em linguagem e tecnologias como a investigação de interações linguísticas com uso de telefones celulares, smartphones e tablets, e suas aplicações pedagógicas (PAIVA, 2013, p. 933).

1 Projeto 404661/2016-5 financiado pelo CNPq no âmbito do edital universal 2016 e coordenado por Vera Menezes de Oliveira e Paiva. 
Em nosso projeto atual, ficamos responsáveis por conhecer como se encontram as pesquisas no Nordeste do Brasil. E para isso, neste recorte, estabelecemos um marco comparativo com o mapeamento anterior de Paiva (2013) e colocamos como meta traçar relações com tendências a continuidade ou inovação nas pesquisas, bem como ressaltar as ferramentas digitais usadas no ensino de inglês. Assim, o estudo em tela se articula a conceitos como de inovação, criação de redes e ampliação de espaços de aprendizagem. Inovação pode ser entendida aqui como "novos conhecimentos ou novas combinações de conhecimentos já existentes" (JUSTESEN, 2004, p. 23). Segundo Justesen (2004, p. 24) "a inovação não se refere apenas à obtenção de novas ideias e invenções, mas também à exploração com sucesso e difusão dessas invenções".

Além disso, com a constituição de redes entre pesquisadores difundindo resultados de pesquisa sobre linguagem e tecnologia e estudos que levantem dados sobre ferramentas digitais novas para ensino de inglês nos últimos cinco anos, estaremos gerando oportunidades de novas combinações de conhecimentos já existentes, como na articulação com disciplinas na graduação e pós-graduação e práticas de ensino e pesquisa na Educação Básica. Na próxima seção, apresentamos a metodologia usada na pesquisa. Em seguida, elaboramos a discussão dos resultados e, finalmente, apresentamos as considerações finais.

\section{Metodologia}

Como apontamos, a meta geral da pesquisa é catalogar, sistematizar e difundir novos conhecimentos sobre linguagem e tecnologias no ensino de línguas, e no ensino de língua inglesa em particular, o que poderá gerar impactos, por exemplo, para constituição de novas redes de pesquisa e construção de disciplinas vinculadas ao tema. Entendemos que para alcançar o objetivo geral é preciso estabelecer um estado da arte da temática em termos de temas, metodologias, ferramentas e tecnologias que sejam identificadas no portal de dissertações e teses da CAPES, bem como nos portais dos programas de Pósgraduação em Letras.

Procedimentos metodológicos adotados aqui envolvem levantamento de bancos de dados eletrônicos, leitura, glosa e escrita de textos que relatem os dados levantados na pesquisa e possam discuti-los à luz, no caso aqui, de um estado da arte anterior. Para dar suporte à pesquisa, nos embasamos em estratégias de pesquisa em estado da arte (FERREIRA, 2002). Ao fazê-lo, pretendemos sistematizar o que tem sido produzido, os procedimentos metodológicos usados, os temas pesquisados, o uso de tecnologias e uma discussão sobre implicações pedagógicas das pesquisas. Ainda nesse processo de análise, buscaremos identificar continuidades e tendências à inovação no campo. A análise dos dados também se articula aos parâmetros e procedimentos da pesquisa qualitativa na Linguística Aplicada (DENZIN; LINCOLN, 2006; DÖRNIEY, 2007).

Assim, temos como meta nesta proposta ampliar, não apenas o conhecimento sobre o que tem sido pesquisado sobre o tema nos últimos cinco anos, mas, além disso, a maneira como se têm desenvolvido os estudos. Dentre estes procedimentos gerais incluídos no trabalho, podemos destacar: 1. Consulta ao banco de teses e dissertações da CAPES; 2. Consulta a arquivos dos programas de mestrado e doutorado em Letras, Linguística e Linguística Aplicada do Nordeste. 3. Consolidação do quantitativo identificado. 4. Estudo dos resumos, da seção de metodologia e resultados das teses e 
dissertações. 5. Identificação dos padrões através de análise de conteúdo 6 . Análise comparativa dos resultados com um estado da arte anterior. 7. Discussão conceitual com colaboradores do projeto.

\subsection{Métodos da Pesquisa}

A pesquisa é de tipo qualitativo e de cunho interpretativo com análise de conteúdo do estado da arte de um banco de dados com recorte delimitado nos últimos cinco anos. Assim, portanto, se utiliza de procedimentos de análise de unidades e temas de um determinado corpus. Ao passo em que nos debruçamos sobre a leitura dos resumos, metodologia e resultados dos trabalhos identificados nas temáticas, no eixo documental, analisaremos as tendências metodológicas, o uso de ferramentas digitais e os resultamos em termos pedagógicos para o ensino de inglês. Nessa linha, após o trabalho de mapeamento e catalogação, operacionalizamos as seguintes ações concatenadas: 1) identificar temas, metodologias e ferramentas digitais para ensino de inglês; 2) relacionar a metodologia identificada no corpus com os temas e resultados; 3) agrupar os estudos que indiquem continuidade e estudos com incidência de tendências a inovação nos procedimentos metodológicos, em seus resultados e implicações pedagógicas; 4) verificar ferramentas digitais usadas no ensino de inglês para produção de textos orais, escritos e multimodais; 5) avaliar os resultados das pesquisas.

\subsection{Procedimentos do Estudo}

No primeiro procedimento, é necessária a elaboração de um banco de dados composto pelos resumos das dissertações e teses, bem como dos arquivos completos desses trabalhos, a fim de, por meio deles, proceder, primeiramente, à leitura detalhada dos resumos com o objetivo de destacar os temas mais estudados. Com base no estabelecimento de recorrência dos temas, observamos os procedimentos metodológicos que mais se destacam por tema. Dessa maneira, o banco de dados é categorizado de maneira a gerar tabelas, em anexo no artigo, por meio das quais a relação entre temas e procedimentos metodológicos possam revelar indicações de continuidades e/ou ampliação das escolhas metodológicas identificadas nos trabalhos catalogados em comparação com o mapeamento anterior. Este procedimento permitirá um balanço dos principais temas estudados e relações com as metodologias usadas nas pesquisas.

A recuperação do catálogo de estudos dos últimos cinco anos sobre linguagem e tecnologias no ensino de inglês no Nordeste foi feita através da utilização de palavraschave e parâmetros de busca. Seguimos um parâmetro temático: linguagem e tecnologias; e nos guiamos pelas palavras-chave: tecnologias, ensino, aprendizagem, inglês, computador, língua inglesa. Os parâmetros linguísticos foram trabalhos redigidos em português ou inglês. As fontes bibliográficas foram os bancos de dissertações e teses da CAPES e Programas de Pós-Graduação em Linguística do Nordeste e o parâmetro cronológico: 2013-2017. A partir do procedimento de recuperação e coleta de textos, foram realizadas leituras exploratórias para identificar textos relevantes a partir das palavras-chave, e leitura de títulos e resumos. 


\subsection{Identificação de Continuidades e Tendências a Inovação}

A partir dos dados coletados, organizados e analisados segundo o procedimento descrito, seguimos com a identificação de padrões que tendem a se repetir pouco nos dados. O proposto aqui é avaliar se os padrões de baixa recorrência podem indicar a geração de propostas e rotas alternativas ao que se identifica como canônico nos estudos. Entendemos aqui estas rotas alternativas como indicadores de criatividade para impulsionar o pensamento sobre a temática da linguagem e tecnologias no ensino de inglês frente aos desafios de novos equipamentos tecnológicos e modos de interação linguística nas práticas sociais mediadas por tecnologias. E nesse sentido, como indicado anteriormente, a inovação pode ser entendida como "novos conhecimentos ou novas combinações de conhecimentos já existentes" (JUSTESEN, 2004, p. 23).

No campo de estudos em linguagem e tecnologias, nota-se como a transformação nos modos de comunicação e interação tecnológica produzem novos contextos de linguagem que podem ser consideradas de um ponto de vista comparativo com um mapeamento anterior. Na primeira parte do trabalho, categorizamos as pesquisas a partir dos temas, na segunda, nos debruçamos sobre os capítulos de metodologia e de resultados, e, por último, analisamos as relações de abordagens metodológicas, resultados e uso de ferramentas digitais no ensino que possam apresentar rotas alternativas aos padrões identificados no estado da arte anterior a esse. Nesse procedimento, focamos o trabalho comparativo em relação aos seguintes itens identificados por Paiva (2013): metodologias de pesquisa; criação de contextos para as pesquisas; pesquisas sobre produção textual na internet e interação virtual; produção de textos orais e escritos; smartphones e tecnologias móveis. Para tanto, um terceiro banco de dados foi criado, que articulou mais analiticamente as metodologias, as tecnologias e os resultados identificados em comparação com os padrões e as tendências identificadas.

Para sistematização foram criados quadros, localizados nos anexos deste artigo, para dar suporte à representação dos conteúdos e para visualização de indicadores de continuidade e/ou inovação em procedimentos metodológicos, ferramentas digitais de ensino e resultados de pesquisa distinguidos a partir da análise do corpus. Estes procedimentos auxiliaram na organização das análises e na identificação de padrões a fim de termos a visão panorâmica da pesquisa e sua interface com o ensino de inglês no Nordeste do Brasil entre 2013-2017.

\section{Consolidação dos Resultados Quantitativos}

Foram excluídos da pesquisa os programas com concentração exclusiva em Literatura, bem como os Mestrados Profissionais em Letras (PROFLETRAS) em rede nacional, que têm como foco a formação de professores de Português do Ensino Fundamental. Entendemos esses bancos de dados como futuros potenciais de pesquisa, pois muitos estudos em nossa temática têm sido produzidos nessas esferas e foram sendo encontrados ao longo do trabalho de catalogação.

Embora tenhamos partido do banco de dissertação e teses da CAPES, encontramos muitas dificuldades nessa plataforma. Parece-nos que há problemas de alimentação desse portal por alguns programas de pós-graduação em Letras. Após uma 
primeira busca no portal da CAPES, partimos, então, para catalogar pesquisas nos bancos dos próprios programas de pós-graduação em Letras. Passamos a descrever esse processo de busca nos portais por ordem alfabética dos estados do Nordeste. Em Alagoas foi pesquisado apenas o Programa de Pós-graduação em Letras e Linguística da Universidade Federal de Alagoas. Entretanto, entre 2016 e 2017, o primeiro momento da busca, feita pela bolsista que colaborou no mapeamento inicial, o portal do programa nos direcionava para o banco de Teses e Dissertações da Fundação de Apoio à Pesquisa de Alagoas. Lá não obtivemos nenhum resultado positivo relacionado à nossa pesquisa. Acessamos o portal novamente no final de 2018 e no início de 2019. Notamos que houve alteração no desenho da página, entretanto, não há nenhum link disponível para acessar teses e dissertações desse programa. Assim, portanto, com a ausência de direcionamentos no portal, e em consonância com os procedimentos estabelecidos para a realização dessa pesquisa, não obtivemos resultados de catalogação nesse portal.

Na Bahia, pesquisamos o Programa de Pós-graduação em Crítica Cultural e o Programa de Pós-graduação em Estudos de Linguagens, ambos da Universidade do Estado da Bahia. Não encontramos nenhum trabalho relacionado à nossa temática nesses programas. Assim também, os Mestrados em Linguística da Universidade Estadual de Feira de Santana e da Universidade Estadual do Sudoeste da Bahia não apresentaram dados. Encontramos seis dissertações relacionadas à nossa pesquisa no Programa de Pós-graduação em Linguagens e Representações da Universidade Estadual de Santa Cruz. Catalogamos duas dissertações no Programa de Pós-graduação em Cultura, Educação e Linguagens da Universidade Estadual do Sudoeste da Bahia e uma dissertação no Programa de Pós-graduação em Língua e Cultura da Universidade Federal da Bahia. No Ceará, identificamos uma dissertação e uma tese no Programa de Pósgraduação em Linguística Aplicada da Universidade Estadual do Ceará, uma dissertação e duas teses no Programa de Pós-graduação em Linguística da Universidade Federal do Ceará.

Na Paraíba, encontramos uma dissertação no Programa de Pós-graduação em Linguística da Universidade Federal da Paraíba e outra no Programa de Pós-graduação em Linguagem e Ensino da Universidade Federal de Campina Grande. Em Pernambuco localizamos uma tese no Programa de Pós-graduação em Linguística da Universidade Federal de Pernambuco, mas nenhum trabalho na temática da pesquisa foi encontrado no Programa de Pós-graduação em Ciências da Linguagem da Universidade Católica de Pernambuco. No Rio Grande do Norte, não encontramos trabalhos no Programa de PósGraduação em Letras da Universidade do Estado do Rio Grande do Norte, mas detectamos quatro dissertações e uma tese no Programa de Pós-Graduação em Estudos da Linguagem da Universidade Federal do Rio Grande do Norte. Finalmente, não foi localizado nenhum trabalho no Programa de Pós-graduação em Letras da Universidade Federal do Sergipe. Não encontramos nenhum trabalho relacionado à nossa temática nos Programas de Pós-graduação em Letras do Maranhão e do Piauí. Assim, conseguimos um corpus com 22 trabalhos: 4 teses e 18 dissertações. A consolidação desses resultados se encontra no Anexo 1. Nas seções que seguem, passamos para os resultados da análise de conteúdo. Em primeiro lugar, discutiremos a relações entre as temáticas e as metodologias de pesquisa. 


\section{Resultados da Análise de Conteúdo}

Na pesquisa de Paiva (2013, p. 932), a esmagadora maioria dos estudos descritos usaram alguma forma de metodologia qualitativa. A única exceção são os estudos sobre leitura que tendem a usar experimentos. O mapeamento realizado no Nordeste confirma esse padrão, apontando assim para uma continuidade dessa tendência. Entretanto, notase aqui a emergência de metodologias combinadas e aumento significativo de pesquisaação. Ao todo, apenas uma pesquisa não usou algum método qualitativo. Nesse caso, um experimento que analisou fatores cognitivos com análise de rastreamento ocular na leitura de hiperlinks em inglês (SANTOS, 2014), o que também confirma a tendência identificada pela autora.

Por outro lado, como apontamos anteriormente, temos a identificação de pesquisas experimentais com algum tipo de avaliação qualitativa da experiência na pesquisa. Nesses casos, quando o foco principal da pesquisa apresentar uma tendência mais experimental, quantitativa e/ou correlacional, classificamos essas como seguindo outro padrão metodológico (LEANDRO, 2014; SOARES, 2013; SOUZA, 2014).

No mapeamento de Paiva (2013, p. 932), para avaliar a percepção de alunos e de professores sobre ensino de línguas mediado pelo computador, há predominância de estudos de caso com observação não-participante, questionários e entrevistas. Nas pesquisas catalogadas no Nordeste, observa-se a situação que descreveremos a seguir

Há um grupo de estudos catalogados que segue exatamente o padrão mostrado por Paiva (2013). São eles os trabalhos de Barbosa (2014), Oliveira (2013) e Peixoto (2013). Barbosa (2014) realizou uma investigação sobre as concepções de uso de tecnologias no ensino de inglês de quatro professoras de língua inglesa de uma escola estadual do interior da Bahia. Trata-se de uma pesquisa de cunho etnográfico, com observação não-participante das aulas, conversas e entrevistas. Oliveira (2013) também buscou avaliar a situação de uso de tecnologias por professores de língua inglesa da Educação de Jovens e Adultos (EJA), seguindo o mesmo protocolo qualitativo de Barbosa (2014). Também com uso de observação não-participante e entrevistas, Peixoto (2013) pesquisou a implementação do projeto Monitor Educacional/TV Pendrive ${ }^{2}$, da Secretaria da Educação do Estado da Bahia, e como essa política se reflete na prática docente de língua inglesa.

O maior número das pesquisas qualitativas se baseou na pesquisa-ação colaborativa com estratégias de observação-participante (COSTA, 2013; FONSECA DIAS, 2014; LEMOS, 2017; PEREIRA, 2016; SILVA, 2013). Entendemos esse padrão como algo que pode indicar uma tendência inovadora nessas pesquisas. Todas elas foram realizadas em colaboração com escolas da Educação Básica em que havia um intercâmbio de conhecimentos entre as universidades e as escolas no desenvolvimento de projetos com tecnologias no ensino de inglês. Nesse processo, destaca-se o trabalho conjunto na tomada de decisões sobre os rumos da pesquisa, como é característico da pesquisaação.

Duas dessas pesquisas trabalharam com equipamentos móveis e seus aplicativos como Costa (2013) e Lemos (2017). Outras duas focaram trabalhos de ensino de inglês

2 O Monitor Educacional/TV Pendrive é um equipamento multimídia que permite a exibição de arquivos digitalizados de áudio, imagem e vídeo através da recepção de sinais como, por exemplo, pendrive, cartão de memória, DVD, câmera digital, TV aberta, TV a cabo, celular, notebook (PEIXOTO, 2013, p. 94). 
com uso do aplicativo de redes sociais, o Facebook (FONSECA DIAS, 2014; PEREIRA, 2016). E uma delas trabalhou a produção de quadrinhos em inglês com o uso do Tondoo, um aplicativo de criação de histórias em quadrinhos (SILVA, 2013). Assim, diferentemente do padrão identificado no mapeamento de Paiva (2013), nessas pesquisas, o trabalho desenvolvido foi o de observação-participante com foco na construção colaborativa entre pesquisadores nas universidades e nas escolas em projetos de ensino-aprendizagem de inglês com uso de tecnologias digitais. Nota-se, ainda, estratégias de pesquisa qualitativa que vão além do uso de questionários e entrevistas.

Outro grupo de pesquisa identificado tem relação com a análise ou produção de material didático com estratégias de avaliação qualitativa pelos usuários do material (ALMEIDA, 2015; SALES, 2015) ou pela pesquisadora ao avaliar Recursos Educacionais Abertos (SANTOS, 2015). Sales (2015) procurou avaliar como o Google Tradutor, aliado à utilização das estratégias de leitura, podem potencializar a leitura de textos em inglês para um fim específico. Para isso, a autora realizou um estudo qualitativo que envolveu o desenvolvimento de uma sequência didática e sua avaliação com uso de questionários e entrevistas. Já Almeida (2015) realizou um estudo de caso com estudantes de Inglês que interagiram com uma sequência didática criada com o aplicativo Lyrics Training, um aplicativo para treinar a fala com canções. Nesse estudo, foram também utilizados questionários para se avaliar a percepção acerca da sequência didática com o aplicativo. Por sua vez, Santos (2015) realizou uma análise das características dos objetos e recursos educacionais em portais para o ensino de inglês à luz de conceitos didáticos que caracterizam os Recursos Educacionais Abertos (REA) que são recursos de ensino e aprendizagem de livre acesso em domínio público e com licença aberta que permite sua adaptação por outros.

Um outro grupo, seguiu o padrão de pesquisas quali-quantitativas com foco em produção textual. Brasil (2015) pesquisou a multimodalidade de fanpages no Facebook por meio de uma análise descritiva quali-quantitativa com base em um protocolo de análise textual multimodal. Na mesma linha, Carvalho (2016) investigou Composições Multimodais Instrucionais (CMIs) em um estudo quantitativo e qualitativo de textos e imagens em plataformas digitais de ensino de inglês com a avaliação qualitativa da percepção dos estudantes acerca desse padrão de composição textual de Ambientes Virtuais de Aprendizagem (AVAs). Martins (2015) usou um protocolo de análise qualiquantitativo para avaliar de que maneira diferentes aplicativos educacionais ensinam a pronúncia do inglês e em que abordagens esses aplicativos se encaixam. Souza Santana (2013), por sua vez, realizou uma análise quanti-qualitativa de blogs digitais de docentes de língua inglesa/portuguesa de escolas do Ensino Médio. Já Oliveira (2014), em sua dissertação, avaliou o impacto das tarefas de aprendizagem mediadas pela lousa digital interativa (LDI) na motivação situacional de aprendizes de inglês com uso de diversos questionários, observações de aulas e correlação quantitativa dos dados de diversas notas de desempenho acadêmico dos participantes no semestre.

Há ainda uma pesquisa caracterizada como qualitativa complexa que investigou a complexidade de affordances, ou como os estudantes percebem possibilidades para interação online escrita em um ambiente virtual de aprendizagem para professores de inglês em formação inicial (TUROLO SILVA, 2015). E também outra pesquisa baseada na pesquisa narrativa que trabalhou as narrativas de professores de inglês em formação sobre a didatização de podcasts para o ensino de inglês na floresta amazônica (UCHOA, 2014). Em seguida, apresentamos outro padrão identificado nas práticas metodológicas 
que foram as pesquisas experimentais, mas que também usaram protocolos de avaliação qualitativa.

\subsection{Experimentos com avaliação qualitativa}

Em comparação com os padrões identificados por Paiva (2013), notou-se a emergência de maior número de estudos experimentais com avaliação qualitativa. Destaca-se aqui a combinação de práticas metodológicas comuns em trabalhos de pesquisa com foco em leitura, como procedimentos de protocolo verbal, com metodologias qualitativas. Nesses protocolos verbais, os estudantes fornecem uma explicação sobre suas operações de leitura e ajudam o pesquisador a compreender os roteiros cognitivos de processamento de linguagem, nesse caso aqui, em pesquisas com produção oral e escrita em inglês.

Já Leandro (2014), em seu estudo de natureza quase-experimental, investigou o impacto da escrita colaborativa com uso da ferramenta Google Docs no desenvolvimento da habilidade de escrita em inglês e na percepção psicolinguística de erros sintáticos, ou noticing $^{3}$, com uso de protocolos de testes e experimentação. Com metodologia similar, Soares (2013) nos apresenta uma pesquisa sobre a aprendizagem de inglês mediada por jogos eletrônicos do tipo MMORPG (Massively Multiplayer Online Role-Playing Games). Seguindo o método experimental, houve uso de protocolos de teste, experimentação e protocolo verbal para relatar o processo de aprendizagem. A análise foi quali-quantitativa no intuito de encontrar correlações entre a interação em inglês nos jogos e o aprendizado dos estudantes.

Também com uso de metodologia experimental, Souza (2014) analisou a ferramenta VoiceThread no desenvolvimento da produção oral e da capacidade de noticing de estruturas e lacunas na aprendizagem de inglês. O estudo procurou verificar se existe uma relação entre as medidas de produção oral dos aprendizes e sua habilidade de noticing com uso de protocolos experimentais e testes. Por fim, as impressões dos aprendizes com a ferramenta foram analisadas por meio de questionários aplicados. $\mathrm{Na}$ seção seguinte exploraremos a criação de contextos especificamente dedicados ao desenvolvimento das pesquisas.

\subsection{Criação de Contextos para as Pesquisas}

Segundo Paiva (2013, p. 933), nas pesquisas avaliadas em seu mapeamento, foi identificada a prevalência de contextos especialmente desenhados para as pesquisas. Segundo a autora, isso pode indicar uma relação com a hipótese de que a tecnologia da Internet ainda não está normalizada no ambiente escolar brasileiro, pois não há indicação de que as experiências teriam prosseguimento após a pesquisa.

No mapeamento realizado para esta pesquisa, também encontramos como padrão a criação de contextos para o desenvolvimento das pesquisas, sejam elas em contextos da Educação Básica ou no Ensino Superior. Entretanto, notamos algumas diferenças com

3 Leandro (2014) define noticing como o processo de aprendizagem em que o aprendiz nota conscientemente um aspecto formal da língua em tarefas contextualizadas. Para um aprofundamento, ver Leandro (2014, p. 19-24). 
relação ao padrão identificado por Paiva (2013). Peixoto (2015), por exemplo, investigou como uma política pública de tecnologia educacional do Estado da Bahia se relaciona com o uso efetivo feito do Monitor Educacional/TV Pendrive por professores de inglês na rede estadual de ensino. De maneira similar, Barbosa (2014) também avaliou como políticas de tecnologias educacionais no âmbito do Programa Nacional de Tecnologia Educacional, o PROINFO, e as orientações pedagógicas para o trabalho com multiletramentos, expresso nos documentos oficiais como em Brasil (2006), se articulam na ação efetiva de professores de inglês na escola. Na mesma linha, Fonseca Dias (2014) trabalhou no andamento de uma política pública nacional, o "Projeto Um Computador por Aluno", o PROUCA. De fato, na escola em que a pesquisa de Fonseca Dias (2014) foi realizada, outras pesquisas estavam sendo conduzidas pelo grupo responsável pela formação de professores do "Projeto Um Computador por Aluno" na Bahia (Cf. VELOSO, BONILLA, PRETTO, 2016).

Além dessas pesquisas, que têm como foco políticas de tecnologias na Educação Básica, encontramos estudos que avaliaram políticas de Ensino Superior como os cursos de formação de professores de inglês à distância (CARVALHO, 2016; TUROLO-SILVA, 2015; UCHOA, 2014), uma nova tendência em comparação com o mapeamento anterior. Nessas pesquisas, temos dois trabalhos com ambientes virtuais de aprendizagem de cursos de formação de professores de inglês (CARVALHO, 2016; TUROLO-SILVA, 2015) e outra pesquisa sobre didatização de gêneros orais mediados por podcasts, que são arquivos de áudios que podem ser compartilhados, também na formação inicial de professores (UCHOA, 2014). Nota-se, assim, que o trabalho realizado nos indica contextos em que as tecnologias parecem integrar um universo de práticas que já se faz presente no ensino e aprendizagem de inglês nas escolas e universidades do Nordeste do Brasil. Entretanto, em todas elas, ainda se observam contextos desafiadores de trabalho com tecnologias, especialmente aquelas que demandam conectividade de banda larga com a internet. É comum ainda, como já identificado no mapeamento de pesquisas anteriores a essa, que as limitações de acesso à conectividade de Internet que seja efetivamente de qualidade permanece sendo um limitador de práticas com linguagem e tecnologias.

Além de questões problemáticas de infraestrutura observadas nos estudos, as pesquisas revisadas nesse estado da arte também continuam a nos indicar limitações no âmbito da formação de professores para uso de tecnologias. Particularmente aqui, notamos modelos de formação de professores que permanecem instrumentais, baseados em modelos de ensino como transmissão e da aprendizagem como consumo, e em formatos que limitam a possibilidade de diálogo e reflexão crítica em conjunto com os professores. Estudos sobre o "Programa Um Computador por Aluno", a última política pública que tivemos na área da tecnologia educacional, nos indicam essas limitações (QUARTIERO; BONILA; FANTIN, 2015; VELOSO, BONILLA, PRETTO, 2016).

\subsection{Pesquisas sobre a produção textual na Internet e sobre a interação virtual}

Um grupo de pesquisas que avaliamos oferece inovações em comparação com a pesquisa de Paiva (2013): são as pesquisas relacionadas com a produção textual em ambientes online e também estudos acerca dos processos de interação virtual na interface com o ensino-aprendizagem de inglês. Nesse âmbito, ainda é possível identificar igualmente um trabalho voltado para a produção de hipertextos em linguagem de sites de 
redes sociais, algo que Paiva (2013) havia nos apontado como lacunar em seu mapeamento. Nessa linha, é saliente o crescimento de pesquisas sobre a linguagem de sites de redes sociais, como o Facebook, estudos de elementos envolvidos na interatividade em Ambientes Virtuais de Aprendizagem, bem como de pesquisas sobre produção textual multimodal. Esse crescimento vai na direção de produções recentes sobre o tema (ARAÚJO; LEFFA, 2016).

Brasil (2015), por exemplo, pesquisou a multimodalidade de fanpages no Facebook, que são páginas específicas destinadas a diferentes agrupamentos sociais que podem ser criadas por qualquer usuário da rede. Através de uma análise textual multimodal do tipo quali-quantitativa, a autora mostra como a presença da multimodalidade, com destaque para as relações de complementariedade de imagens subordinadas às partes do texto pertencentes a determinados sistemas de relações lógico-semânticos. A partir da identificação e da quantificação dessas relações, a autora traça implicações sobre o aspecto pedagógico das fanpages para o ensino de inglês no tocante ao papel de integração multimodal de conteúdos em sites de redes sociais. Fica explícito no estudo de Brasil (2015) como uma pesquisa de detalhamento da linguagem que ocorre nas fanpages pode fortalecer a arena pedagógica do ensino de inglês.

Embora em uma linha diferente, Pereira (2016), em sua dissertação intitulada "O uso do Facebook em aulas de língua inglesa na perspectiva dos multiletramentos", investigou as possibilidades de uso do Facebook por uma professora da rede pública em Juazeirinho na Paraíba. A pesquisa buscou avaliar como o desenho das atividades propostas contribuíram para se obter mais interação entre os participantes. O foco de Pereira (2016) foi o estudo sobre como elementos de interatividade do ambiente digital dessa rede social poderiam promover maior interação entre os estudantes. Esse aspecto de maior interação entre participantes com uso do Facebook integrado a outras tecnologias e práticas cotidianas da sala de aula foi também foco de pesquisa de Fonseca Dias (2014). Nessa pesquisa, observou-se aumento na confiança dos estudantes para o uso de Inglês em atividades de imersão na cibercultura. Outro dado dessa pesquisa que se articula também com a pesquisa de Pereira (2016) é o esforço da comunidade escolar para articular os usos de sites de redes sociais com recursos tradicionais da escola, frente às limitações de ordem estrutural e de letramentos digitais. Os resultados dessas pesquisas deixam explícito o potencial positivo de sites de redes sociais como 0 Facebook para o ensino e aprendizagem de inglês coerentes com a pujança de práticas sociais com linguagens e tecnologias digitais. Os resultados indicam que há uma mudança nas dinâmicas de uso de inglês que tornam os estudantes mais dispostos a se comunicarem que em contextos face a face, assim como as interações em sites de redes sociais.

Lemos (2017), em sua pesquisa-ação colaborativa com uma escola estadual em Uruçuca na Bahia, desenvolveu diversas estratégias de ensino-aprendizagem de Inglês com uso de smartphones. Com uma turma do Ensino Médio, utilizando o aplicativo de mensagens WhatsApp, foram desenvolvidas diversas estratégias de ensino que se tornaram uma unidade didática sob a temática central "Uso ético e seguro das redes sociais digitais". Foram trabalhados temas como, por exemplo, a superexposição na rede bem como assédio virtual de adolescentes. Os recursos de áudio, vídeo e texto multimodal do WhatsApp foram explorados através de diferentes práticas sociais com 
linguagens e tecnologias como a produção de vídeo-poemas ${ }^{4}$, minicontos multimodais ${ }^{5}$, memes $^{6}$, selfies ${ }^{7}$, braggies ${ }^{8}$ e infográficos ${ }^{9}$ (LEMOS, 2017, p. 63). A percepção dos estudantes sobre a experiência na pesquisa apontou, assim como nos estudos de Pereira (2016) e Fonseca Dias (2014), para um aumento da disposição comunicativa e maior nível de interatividade dos estudantes em inglês com uso articulado de estratégias de produção textual digital. Além disso, um fator novo identificado no trabalho de Lemos (2017) foi o desenvolvimento de uma pesquisa-ação com enfoque na conscientização dos estudantes sobre uso ético e seguro de sites de redes sociais através de diversas tecnologias digitais.

Com relação à interatividade em ambientes digitais, Turolo-Silva (2015/UFC) em sua tese intitulada "Affordances e restrições na interação interpessoal escrita online durante a aprendizagem de inglês como língua estrangeira" mostra como os mecanismos de engajamento com affordances ajudam a sustentar a interação escrita em um ambiente virtual de aprendizagem de inglês em fóruns de discussão e nos chats. Os resultados apontam para a complexidade das affordances: o que era percebido por alguns como um favorecimento, para outros era uma restrição. Os resultados gerais indicaram que as affordances contribuíram para a construção da presença no ambiente, na projeção das identidades e de uma comunidade de aprendizagem que, por sua vez, se transformou em uma affordance que embasou o sentimento de confiança no engajamento nas interações.

Carvalho (2016), por sua vez, nos mostra como a EaD tem transformado aulas presenciais em disciplinas virtuais compostas por Composições Multimodais Instrucionais (CMIs) com textos e imagens no material didático online do Curso de Licenciatura em Letras - Língua Inglesa e suas Literaturas (modalidade a distância) do Instituto UFC Virtual da Universidade Federal do Ceará. Os resultados das análises apontam para o uso frequente de CMIs. Contudo, na maioria dos casos, elas ainda estão dissociadas dos objetivos de ensino. Os dados evidenciam também que os estudantes percebem a necessidade da inserção de CMIs em seus materiais didáticos e percebem inclusive suas funções didáticas. Embora o material analisado esteja hospedado em um ambiente online de aprendizagem a Universidade, os materiais permanecem com uma forte base verbal escrita sem uso de CMIs. As imagens e as CMIs ainda são utilizadas como acessório decorativo, reforçando um ensino presencial que entra em conflito com as possibilidades que os textos multimodais oferecem em ambientes digitais.

\subsection{Produção de textos orais}

Em seu mapeamento, Paiva (2013) mostrou que, no período analisado de 2000 a 2012, ainda não havia trabalhos investigando a produção de textos orais. Nesse mapeamento, identificamos trabalhos que pesquisaram a produção de textos orais com

4 Poemas em formato de vídeo. Podem ou não incluir textos escritos.

5 Contos curtos que combinam imagens, textos e vídeos.

6 Articulações de texto escritos e imagéticos que têm por função propagar informações, acontecimentos e expressões socioculturais de modo resumido e rápido.

7 Práticas de autorretrato digital frequentemente compartilhada em sites de redes sociais.

8 Uma forma de autorretrato com um pano de fundo que se destaca.

9 Textos informativos que combinam elementos imagéticos e textos escritos muito presentes em materiais impressos e online. 
tecnologias digitais. Primeiramente, temos a tese de doutorado de Uchôa (2014) que focou a experiência de professores de inglês em formação inicial sobre a didatização de podcasts (arquivos orais em áudio) para o ensino de inglês na floresta amazônica. Com base na Pesquisa Narrativa, o autor relatou os procedimentos adotados durante a vivência em um processo de didatização de gêneros discursivos orais difundidos pela prática de podcasting. $\mathrm{O}$ autor mostrou como os registros dos gêneros utilizados no estudo possuem temáticas voltadas para o contexto da floresta Amazônica, oportunizando a construção de estratégias de ensino apropriadas ao contexto local com uso de tecnologias digitais para o trabalho com gêneros orais. Os resultados demonstraram a pouca vivência dos participantes em processos de didatização de gêneros orais, uma vez que estes estão mais acostumados com gêneros textuais de ambientes escritos. Outro resultado foi a relevância de temas amazônicos para o trabalho na formação do professor na Amazônia. Além disso, notou-se que o trabalho colaborativo pode ser uma aliada estratégia para superar limitações de letramento digital. Ou seja, em uma comunidade de aprendizagem, uns passam a aprender constantemente com os outros, não apenas com o professor.

Outra pesquisa nessa linha é o de Souza (2014) que pesquisou o uso da ferramenta VoiceThread para produção de textos orais em inglês com professores em formação inicial na universidade. O VoiceThread é uma ferramenta colaborativa e assíncrona que permite a criação de apresentações orais com auxílio de imagens, documentos, textos, possibilitando que grupos de pessoas contribuam com comentários orais de várias maneiras. O VoiceThread permite que o estudante planeje sua fala antes de gravá-la. Além disso, as apresentações podem ser gravadas e regravadas várias vezes, o que encoraja que ele perceba as lacunas em sua produção oral (o que se chama de noticing na pesquisa) e a edite inúmeras vezes antes de publicá-la.

Assim, Souza (2014) procurou verificar se existe uma relação entre as medidas de produção oral dos aprendizes e sua habilidade de noticing em lacunas léxico-gramaticais. Os resultados apontaram que há uma correlação estatisticamente significativa entre as medidas de produção oral dos aprendizes e sua habilidade de noticing. Além disso, verificou-se que há um impacto positivo da ferramenta VoiceThread sobre as variáveis da produção oral dos aprendizes e sua habilidade de noticing. A análise qualitativa indicou uma reação positiva dos aprendizes em relação à experiência com a ferramenta. Lemos (2017) também explorou os recursos de áudio do aplicativo WhatsApp para atividades de produção oral em inglês na sua pesquisa. Várias atividades produzidas para a pesquisa fomentaram produção oral dos estudantes do Ensino Médio. Os resultados de Lemos (2017) também apresentaram maior envolvimento dos estudantes no uso oral do inglês, com diminuição do sentimento de inibição e vergonha ao falar.

Outras duas pesquisas catalogadas trabalharam com a pronúncia em inglês por meio de aplicativos que auxiliam nesse processo de aprendizagem. Almeida (2015), em um estudo de caso, investigou como tecnologias digitais aliadas à música podem potencializar a aprendizagem de Língua Inglesa de alunos do Ensino Médio da rede pública de ensino na Bahia, particularmente com relação à aquisição de vocabulário, fonética e compreensão auditiva. Os estudantes de Inglês participantes do estudo usaram uma sequência didática que continha uma canção e tarefas de compreensão e aquisição de vocabulário com uso do aplicativo Lyrics Training. Os resultados positivos indicam que o trabalho com o aplicativo pode trazer contribuições para a compreensão auditiva e aquisição de vocabulário. Além disso, os relatos indicam que a maior construção do conhecimento aguçou mais à vontade de se apropriar da Língua Inglesa. Estudantes 
indicaram a atividade como fácil, divertida e inovadora.

A outra pesquisa com foco em pronúncia é a de Martins (2015) que avaliou de que maneira softwares educativos ensinam a pronúncia do inglês, como, por exemplo, 0 "Pronunciation Power 2". A meta global foi avaliar se os aplicativos de pronúncia selecionados seguem os princípios da Abordagem Comunicativa. Foi criado um instrumento de avaliação dos softwares e os professores de inglês os avaliaram. Em seguida, as respostas foram estatisticamente analisadas. No computo global, somente um dos softwares obteve mais de $75 \%$ (setenta e cinco por cento) da pontuação total do instrumento. Os outros quatro apresentaram menos de três quartos do total das características de acordo com o protocolo elaborado. Os resultados indicam que, embora os softwares não sigam todos os princípios da abordagem comunicativa, eles podem ser usados para enriquecer o ensino da pronúncia do inglês.

\subsection{Produção de textos escritos}

Outra lacuna encontrada é a pesquisa acerca da produção de textos em ambientes digitais, ou de vídeos e quadrinhos com ferramentas digitais (PAIVA, 2013, p. 933). Em nossa pesquisa encontramos um estudo que usou um aplicativo de criação de quadrinhos, o Toondoo. Silva (2013), em sua dissertação intitulada "Ensino de língua inglesa em HQ: possibilidade de um ensino significativo com a ferramenta digital TOONDOO", procurou avaliar o uso desta ferramenta digital de produção de textos. Os resultados da pesquisa com alunos em uma escola de ensino fundamental indicam aumento de motivação na leitura e na escrita em inglês com expansão de criatividade na elaboração de cenários e personagens que devem ser associados ao texto verbal e não verbal, promovendo produção textual multimodal.

Outro estudo que teve como foco a produção escrita em ambiente digital foi a pesquisa de Leandro (2014). O autor elaborou sua pesquisa a partir do argumento de que os aprendizes têm mais oportunidades para perceber as lacunas na sua produção escrita quando trabalham em conjunto com outros colegas de maneira colaborativa. O estudo investigou o impacto da escrita colaborativa pela ferramenta Google Docs na habilidade de escrita em inglês e na percepção (ou noticing) de erros sintáticos. Os resultados quantitativos mostram que os aprendizes passaram a produzir textos com mais densidade lexical. Os resultados qualitativos evidenciam a utilidade da escrita colaborativa mediada por tecnologia no processo de aprendizagem de inglês.

\subsection{Smartphones e Tecnologias Móveis}

Outras lacunas observadas por Paiva (2013, p. 933) são estudos "sobre uso de mensagens mediadas por telefones celulares e também sua aplicação no ensino; e o uso de aplicativos para tablets. Costa (2013) em sua tese de doutorado "Mobile learning: explorando potencialidades com o uso do celular no ensino de inglês com alunos da escola pública", pesquisou diversas atividades pedagógicas mediadas pelo celular. A pesquisa constatou que ensinar com ajuda do celular é uma possibilidade real e ajudou a melhorar a aquisição de inglês. Além disso, o trabalho com o celular colocou os alunos em um contexto real e tornou o processo mais atraente e motivador. Com a tecnologia móvel em mãos, os estudantes participantes da pesquisa otimizaram o tempo de estudo ao acessarem suas atividades didáticas em qualquer lugar e a qualquer hora. Os resultados 
gerais mostraram que o uso do celular no ensino de inglês proporciona uma flexibilidade produtiva no ensino-aprendizagem de inglês, algo pouco provável de ocorrer em um ambiente de ensino tradicional. Tecnologias digitais para produção de textos orais tendem a ampliar os espaços e tempos dedicados à produção oral em Língua Estrangeira.

Já Lemos (2017), em sua pesquisa-ação, também trabalhou com smartphones pelo aplicativo WhatsApp. Os recursos de áudio, vídeo e texto multimodal do WhatsApp foram explorados por meio de diferentes práticas sociais com linguagens e tecnologias nesse ambiente digital.

No Anexo 2, apresentamos um quadro para visualização tabulada das pesquisas catalogadas em termos de metodologias, temas, ferramentas e principais resultados.

\section{Considerações Finais}

Os resultados desse estado da arte indicam que as pesquisas avaliadas tendem a oferecer continuidades e também inovações em comparação com o mapeamento de Paiva (2013). Embora as pesquisas continuem a ser predominantemente de natureza qualitativa, nessa pesquisa que realizamos, encontramos um número significativo de estudos baseados na pesquisa-ação colaborativa com diversidade de estratégias de observação-participante (COSTA, 2013; FONSECA DIAS, 2014; LEMOS, 2017; PEREIRA, 2016; SILVA, 2013). Nota-se aqui um aumento de pesquisas realizadas em conjunto com escolas em quadros colaborativos e com foco também na formação de professores e com experiências de trabalho com tecnologias recentes, como as tecnologias móveis.

Outro grupo de estudos combinou estratégias metodológicas quali-quantitativas com foco em produção textual e em fatores de interatividade em diferentes ambientes digitais como em AVAs e sites de redes sociais (BRASIL, 2015; CARVALHO, 2016; MARTINS, 2015). Além disso, notou-se a emergência de um número de estudos com desenhos experimentais e avaliação qualitativa dos experimentos com tecnologias digitais no ensino de inglês (LEANDRO, 2014; SOARES, 2013, SOUZA, 2014).

Embora as pesquisas continuem, em sua maioria, gerando contextos para experimentação com tecnologias, identificamos trabalhos de investigação de políticas públicas de tecnologias digitais e ensino de inglês na Educação Básica (BARBOSA, 2014; OLIVEIRA, 2013; PEIXOTO, 2013) e no Ensino Superior (CARVALHO, 2016; TUROLOSILVA, 2015; UCHOA, 2014). Esses resultados podem nos indicar a expansão do uso e a consolidação de algumas práticas pedagógicas com tecnologias na Educação Básica e no Ensino Superior, mesmo considerando que os desafios de infraestrutura e formação de professores permanecem.

Outra área emergente é a de pesquisas sobre produção textual multimodal (BRASIL, 2015; CARVALHO, 2016; PEREIRA, 2016) e do estudo de elementos envolvidos na interatividade em ambientes digitais, como em Turolo-Silva (2015), Lemos (2017), Fonseca Dias (2014). Identificamos aqui grupos de estudos no Nordeste que têm ampliado a pesquisa sobre o tema da produção textual multimodal em ambientes digitais.

Destaca-se ainda a identificação de trabalhos com produção de textos orais com tecnologias digitais (UCHÔA, 2014, SOUZA, 2014, LEMOS, 2017), treinamento da pronúncia com aplicativos (ALMEIDA, 2015; MARTINS, 2015), produção de textos 
escritos em quadrinhos digitais (SILVA, 2013), e produção colaborativa de textos online (LEANDRO, 2014). Outra área de estudos com indicação de tendências inovadoras são as pesquisas-ações com smartphones como em Costa (2013) e Lemos (2017).

Temos, ainda, uma gama de estudos que nos mostram como o uso de tecnologias digitais no ensino de inglês tende a aumentar a interatividade na língua em uso concomitantemente com o aumento da motivação de estudantes no engajamento em tarefas comunicativas (ALMEIDA, 2015; COSTA, 2013; LEMOS, 2017; PEREIRA, 2016; PEIXOTO, 2013; SILVA, 2013; SOARES, 2013; SOUZA, 2014). Estudos focados na produção oral em inglês aliadas a diversas estratégias de desenvolvimento de habilidades orais com tecnologias digitais móveis tendem a impactar positivamente e fortalecer projetos de formação inicial e continuada de professores de inglês (ARAGÃO, 2017; GOMES JÚNIOR ET AL, 2018).

Acreditamos que em pesquisas futuras, poderemos investigar as pesquisas geradas nos Mestrados Profissionais em Letras (PROFLETRAS), que tenham como foco a formação de professores de Português do Ensino Fundamental, bem como uma série de estudos recentes sobre produção textual multimodal e interatividade comunicativa em ambientes digitais, buscando uma maior articulação de pesquisas entre as áreas de Língua Materna e Língua Estrangeira. Esperamos também em breve poder comparar esses resultados com o mapeamento de estudos produzidos em outras regiões do Brasil.

Finalmente, destacamos que um ponto limitador da pesquisa foi a dificuldade de lidar com o banco de dissertações e teses da CAPES, e limitações de alimentação de dados das dissertações e teses em alguns programas de Pós-graduação em Letras.

\section{Agradecimentos}

Gostaria de agradecer a Vera Menezes de Oliveira e Paiva pela revisão e sugestões em versão anterior deste artigo. Agradeço os pareceristas anônimos bem como as revisoras pelas indicações que me levaram ao aperfeiçoamento final deste texto.

\section{Referências}

ALMEIDA, G. L. As tecnologias digitais e a música como recursos potencializadores da aprendizagem de língua inglesa: um estudo de caso com estudantes do ensino médio. 2015. Dissertação (Mestrado em Letras: Cultural, Educação e Linguagens) - Universidade Estadual do Sudoeste da Bahia, Vitória da Conquista. Disponível em: http://www2.uesb.br/ppg/ppgcel/wpcontent/uploads/2017/07/Disserta\%C3\%A7\%C3\%A30Mestrado-em-Letras-UESB-Turma-2015-Gislene-Lima-Almeida-ilovepdf-compressed.pdf Acesso em: 17 de jun. 2019.

ARAGÃO, R. Emoções e ações de professores ao falar inglês no WhatsApp. Revista Brasileira de Linguística Aplicada, v. 17, p. 83-112, 2017. Disponível em: https://www.scielo.br/pdf/rbla/v17n1/1984-6398-rbla-17-01-00083.pdf Acesso em: 28 maio 2020.

ARAÚJO, J.; LEFFA, V. (Org.). Redes sociais e ensino de línguas: o que temos de 
aprender? São Paulo: Parábola Editorial, 2016.

BARBOSA, E. Letramentos e Multiletramentos: um estudo etnográfico em uma escola da cidade de Itabuna/BA. 2014. Dissertação (Mestrado em Mestrado em Letras: Linguagens e Representações) - Universidade Estadual de Santa Cruz, Ilhéus. Disponível em: http://www.biblioteca.uesc.br/biblioteca/bdtd/201260155D.pdf. Acesso em: 17 jun. 2019.

BRASIL, J. B. Multimodalidade e redes sociais: análise de fanpages do facebook destinadas ao ensino de língua inglesa. 2013. Dissertação (Mestrado em Linguística Aplicada) - Universidade Estadual do Ceará, Fortaleza. Disponível em: http://www.uece.br/posla/dmdocuments/JACIARA\%20DE\%20BARROS\%20.pdf. Acesso em: 13 jun. 2019.

BRASIL. Orientações Curriculares para o Ensino Médio: linguagens, códigos e suas tecnologias. Secretaria de Educação Básica. Brasília, Ministério da Educação, 2006. Disponível em: http://portal.mec.gov.br/seb/arquivos/pdf/book_volume 01 internet.pdf. Acesso em: 13 jun. 2019.

BRASIL. Base nacional comum curricular (BNCC). Brasília: Ministério da Educação (MEC), 2018. Disponível em: http://basenacionalcomum.mec.gov.br/images/BNCC_EI_EF_110518_versaofinal_site.pdf. Acesso em: 18 jul. 2019.

CARVALHO, S. A. As interações imagem-texto em material didático online para formação de professores de Inglês. 2016. Tese (Doutorado em Linguística Aplicada) - Universidade Estadual do Ceará, Fortaleza. Disponível em: http://www.uece.br/posla/dmdocuments/TESE_S\%C3\%82MIA \%20A_CARVALHO_TESE.pdf. Acesso em: 13 jun. 2019.

COSTA, G. S. Mobile learning: explorando potencialidades com o uso do celular no ensino - aprendizagem de língua inglesa como língua estrangeira com alunos da escola pública. 2013. Tese. (Doutorado em Linguística) - Universidade Federal de Pernambuco, Recife. Disponível em: https://repositorio.ufpe.br/handle/123456789/11333. Acesso em: 13 jun. 2019.

DENZIN, N. K.; LINCOLN, Y. O planejamento da pesquisa qualitativas: teorias e abordagens. Porto Alegre: Artmed, 2006.

DÖRNYEI, Z. Research Methods in Applied Linguistics: quantitative, qualitative and mixed methodologies. New York: Oxford University Press, 2007.

FERREIRA, N. S. A. As pesquisas denominadas "estado da arte". Educação \& Sociedade, v. 23, n. 79, p. 257-272, 2002. Disponível em: http://www.scielo.br/pdf/es/v23n79/10857.pdf. Acesso em: 17 jun. 2019.

FONSECA DIAS, I. A. Cibercultura e redes sociais no ensino e aprendizagem de inglês. 2014. Dissertação (Mestrado em Letras: Linguagens e Representações) - Universidade Estadual de Santa Cruz, llhéus. Disponível em: 
http://www.biblioteca.uesc.br/biblioteca/bdtd/201260159D.pdf. Acesso em: 13 jun. 2019.

GOMES JUNIOR, R. C.; TEIXEIRA, G. S.; SILVA, M. G.; PAULINO, C. A. Affordances de tecnologias digitais para o desenvolvimento de habilidades orais em inglês. Revista Brasileira de Linguística Aplicada, v. 18, p. 57-78, 2018. Disponível em: https://www.scielo.br/pdf/rbla/v18n1/1984-6398-rbla-1984-6398201812398.pdf. Acesso em: 28 maio 2020.

JUSTESEN, S. Innoversity in communities of practice. In: HILDRETH, P.M.; KIMBLE, C. (Eds). Knowledge networks: innovation through communities of practice. Hershey: Idea Group, 2004. p.79-95.

LEANDRO, D. C. Escrita Colaborativa com Googledocs: flashfiction, noticing e aprendizagem de inglês como L2. 2014. Dissertação (Mestrado em Estudos da Linguagem) - Universidade Federal do Rio Grande do Norte, Natal. Disponível em: https://repositorio.ufrn.br/jspui/bitstream/123456789/19924/1/DiegoCesarLeandro_DISSE RT.pdf. Acesso em: 13 de jun. 2019.

LEMOS, L. S. Estratégias de Ensino/aprendizagem com o WhatsApp: emoções e multiletramentos. 2017. Dissertação (Mestrado em Letras: Linguagens e Representações) - Universidade Estadual de Santa Cruz, Ilhéus. Disponível em: http://www.biblioteca.uesc.br/biblioteca/bdtd/201510112D.pdf. Acesso em: 13 de jun. 2019.

MARTINS, C. G. F. Avaliação de softwares educativos para desenvolvimento da pronúncia do inglês como língua estrangeira e/ou segunda língua. 2015. Tese (Doutorado em Linguística) - Universidade Federal do Ceará, Fortaleza. Disponível em: http://www.repositorio.ufc.br/handle/riufc/13202. Acesso em: 13 de jun. 2019.

OLIVEIRA, J. W. S. Letramentos Digitais e a EJA em Itabuna. 2013. Dissertação (Mestrado em Mestrado em Letras: Linguagens e Representações) - Universidade Estadual de Santa Cruz, llhéus. Disponível em: http://www.biblioteca.uesc.br/biblioteca/bdtd/201160013D.pdf. Acesso em 13 de jun. 2019

OLIVEIRA, S. F. O fator motivacional da lousa interativa no processo de ensino aprendizagem de inglês como LE. 2014. Dissertação (Mestrado em Estudos da Linguagem) - Universidade Federal do Rio Grande do Norte, Natal. Disponível em: https://repositorio.ufrn.br/jspui/bitstream/123456789/16327/1/SamaraFO_DISSERT.pdf.

Acesso em: 11 jun. 2019.

PAIVA, V. L. M. A pesquisa em linguagem e tecnologia na Universidade Federal de Minas Gerais. Revista Brasileira de Pós-Graduação, v. 10, n. 22, p. 921-941, 2013. Disponível em: http://ojs.rbpg.capes.gov.br/index.php/rbpg/article/view/457. Acesso em: 11 jun. 2019.

PEIXOTO, R. P. Monitor educacional (TV Pendrive): a tecnologia nas aulas de língua inglesa na escola pública. 2013. Dissertação (Mestrado em Língua e Cultura) Universidade Federal da Bahia, Salvador. Disponível em: https://repositorio.ufba.br/ri/handle/ri/15536. Acesso em: 13 jun. 2019. 
PEREIRA, C. S. O uso do facebook em aulas de língua inglesa na perspectiva dos multiletramentos. 2016. Dissertação. (Mestrado em Linguagem e Ensino) - Universidade Federal de Campina Grande, Campina Grande. Disponível em: https://drive.google.com/file/d/OB9 6p7k-tgLQYjFFLVNMaE15bmc/view. Acesso em: 13 jun. 2019.

QUARTIERO, E. M; BONILLA, M. H. S; FANTIN, M. Projeto UCA: entusiasmos e desencantos de uma política pública. Salvador: Edufba, 2015.

VELOSO, M; BONILLA, M. H. S; PRETTO, N. L. A cultura da liberdade de criação e o cerceamento tecnológico e normativo: potencialidades para a autoria na educação. Educação Temática Digital, v. 18, p. 43-59, 2016. Disponível em: https://periodicos.sbu.unicamp.br/ojs/index.php/etd/article/view/8639486. Acesso em: 13 jun. 2019.

SALES, S. G. GoogleTradutor e estratégias de leitura como possibilidade na construção de sentidos na leitura para um fim específico. 2015. Dissertação (Mestrado em LETRAS: CULTURA, EDUCAÇÃO E LINGUAGENS) - Universidade Estadual do Sudoeste da Bahia, Vitória da Conquista. Disponível em: http://www2.uesb.br/ppg/ppgcel/wpcontent/uploads/2017/07/Disserta\%C3\%A7\%C3\%A3o-Mestrado-em-Letras-UESB-Turma2013-Silvia-Gusm\%C3\%A3o-Sales.pdf. Acesso em: 13 jun. 2019.

SANTANA, M. O. S. (Des)encontros entre as OCEM e as Representações de Práticas Textuais com Blog no Ensino e Aprendizagem de Línguas. 2013. Dissertação (Mestrado em Mestrado em Letras: Linguagens e Representações) - Universidade Estadual de Santa Cruz, Ilhéus. Disponível: http://www.biblioteca.uesc.br/biblioteca/bdtd/201160017D.pdf. Acesso em: 13 de jun. 2019.

SANTOS, M. G. Processamento online de textos eletrônicos hiperlinkados e nãohiperlinkados em língua estrangeira. 2014. Dissertação (Mestrado em Lingüística) Universidade Federal do Ceará, Fortaleza. Disponível em: http://www.repositorio.ufc.br/bitstream/riufc/10504/1/2014_dis_egsantos.pdf. Acesso em: 13 jun. 2019.

SANTOS, M. M. Portais de Iniciativa REA: contribuições para o ensino/aprendizagem de Inglês. 2015. Dissertação (Mestrado em Mestrado em Letras: Linguagens e Representações) - Universidade Estadual de Santa Cruz, Ilhéus. Disponível em: http://www.biblioteca.uesc.br/biblioteca/bdtd/201360039D.pdf. Acesso em: 13 jun. 2019.

TUROLO, A. S. Affordances e restrições na interação interpessoal escrita online durante a aprendizagem de inglês como língua estrangeira. 2015. Tese (Doutorado em Linguística) Universidade Federal do Ceará, Fortaleza. Disponível em: http://www.repositorio.ufc.br/bitstream/riufc/15116/1/2015_tese_atsilva.pdf. Acesso em: 13 jun. 2019.

SILVA, P. S. O ensino de língua inglesa em HQ: possibilidade de um ensino significativo 
com a ferramenta digital TOONDOO. 2013. Dissertação (Mestrado em Linguística) Universidade Federal da Paraíba, João Pessoa. Disponível em: http://bdtd.ibict.br/vufind/Record/UFPB-2_cbc6d62269412c9f11174a483a502154. Acesso em: 13 de jun. 2019.

SOARES, W. C. S. A aprendizagem de inglês mediada por jogos eletrônicos do tipo MMORPG. 2013. Dissertação (Mestrado em Programa de Pós-graduação em Estudos da Linguagem) - Universidade Federal do Rio Grande do Norte, Natal. Disponível em: https://repositorio.ufrn.br/jspui/handle/123456789/16264. Acesso em: 13 de jun. 2019.

SOUZA, L. A. A relação entre o desempenho oral em L2 e o uso da ferramenta Voicethread. 2014. Dissertação (Mestrado em Estudos da Linguagem) - Universidade Federal do Rio Grande do Norte, Natal. Disponível em: http://bdtd.ibict.br/vufind/Record/UFRN_1c2738824d485bd0392a625456ee7c86. Acesso em: 08 jul. 2019.

UCHOA, J. M. Narrativas de professores em formação sobre a didatização de podcasts para o ensino de inglês na floresta. 2014. Tese (Doutorado em Estudos da Linguagem) Universidade Federal do Rio Grande do Norte, Natal. Disponível em: https://repositorio.ufrn.br/jspui/handle/123456789/16387. Acesso em: 08 jul. 2019.

Recebido em dia 18 de fevereiro de 2020. Aprovado em dia 04 de maio de 2020. 
ANEXO 1

\begin{tabular}{|c|c|c|c|c|c|c|c|}
\hline \multicolumn{8}{|c|}{ Quadro Comparativo do Mapeamento Nordeste } \\
\hline Região & Estado/PP & \multicolumn{3}{|c|}{ Resultados } & \multirow[t]{2}{*}{ Metodologia } & \multirow[t]{2}{*}{ Temas } & \multirow[t]{2}{*}{ Ferramentas } \\
\hline \multirow{11}{*}{$\begin{array}{l}\text { Nordes } \\
\text { te }\end{array}$} & & Tese & $\begin{array}{c}\text { Dissert } \\
\text { ação }\end{array}$ & Total & & & \\
\hline & Alagoas & --- & +---- & ---- & |---------------- & - & 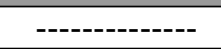 \\
\hline & $\begin{array}{l}\text { Bahia } \\
\text { 6D (UESC) } \\
\text { 2D (UESB) } \\
\text { 1D (UFBA) }\end{array}$ & -- & 9 & 9 & $\begin{array}{l}\text { Estudo de caso do } \\
\text { tipo etnográfico; } \\
\text { qualitativa, } \\
\text { etnografia de sala } \\
\text { de aula }\end{array}$ & $\begin{array}{l}\text { Letramentos; } \\
\text { Ensino de } \\
\text { Línguas; } \\
\text { Multiletramentos; }\end{array}$ & $\begin{array}{l}\text { Blogs, } \\
\text { Facebook; } \\
\text { Portais de } \\
\text { investigação }\end{array}$ \\
\hline & $\begin{array}{l}\text { Ceará } \\
1 \mathrm{D} / 1 \mathrm{~T} \\
\text { (UECE) } \\
1 \mathrm{D} / 2 \mathrm{~T} \\
\text { (UFC) }\end{array}$ & 3 & 2 & 5 & $\begin{array}{l}\text { Descritiva quali- } \\
\text { quantitativa; } \\
\text { exploratória e } \\
\text { descritiva; } \\
\text { qualitativa } \\
\text { complexa; }\end{array}$ & $\begin{array}{l}\text { Multiletramentos; } \\
\text { Multimodalidade; } \\
\text { Abordagem } \\
\text { Comunicativa; } \\
\text { Affordance; } \\
\text { interação online; }\end{array}$ & $\begin{array}{l}\text { Facebook; } \\
\text { software } \\
\text { Pronunciatio } \\
\text { n Power; }\end{array}$ \\
\hline & $\begin{array}{l}\text { Paraíba } \\
\text { 1D (UFPB) } \\
\text { 1D (UFCG) }\end{array}$ & & 2 & 2 & $\begin{array}{l}\text { Qualitativa com } \\
\text { uma abordagem } \\
\text { etnográfica; } \\
\text { Pesquisa-ação }\end{array}$ & $\begin{array}{l}\text { TIC; Língua } \\
\text { Inglesa; Redes } \\
\text { Sociais; } \\
\text { Multiletramentos }\end{array}$ & $\begin{array}{l}\text { Plataforma } \\
\text { de HQ } \\
\text { (TOONDOO); } \\
\text { Facebook }\end{array}$ \\
\hline & Piauí & & & & |----------------------- & -------------------- & ----------- \\
\hline & $\begin{array}{l}\text { Pernambuc } \\
0 \\
1 T\end{array}$ & 1 & & 1 & $\begin{array}{l}\text { Natureza descritiva } \\
\text { de abordagem } \\
\text { Quali-quantitativa }\end{array}$ & $\begin{array}{l}\text { Affordance; } \\
\text { Ensino de Inglês; } \\
\text { Letramento Visual }\end{array}$ & Celular \\
\hline & $\begin{array}{l}\text { Rio Grande } \\
\text { do Norte } \\
1 T \text { (UFRN) } \\
\text { 4D (UFRN) }\end{array}$ & 01 & 04 & 05 & $\begin{array}{l}\text { Quali-quantitativa, } \\
\text { narrativa; } \\
\text { experimental; } \\
\text { métodos múltiplos; }\end{array}$ & $\begin{array}{l}\text { Noticing; } \\
\text { motivação; } \\
\text { podcasting; } \\
\text { compreensão } \\
\text { oral; escrita } \\
\text { colaborativa }\end{array}$ & $\begin{array}{l}\text { Voice } \\
\text { Thread; } \\
\text { Google } \\
\text { Docs; game } \\
\text { online } \\
\text { MMORPGs; } \\
\text { lousa digital } \\
\end{array}$ \\
\hline & Sergipe & & & & & & \\
\hline & & 5 & 17 & & - & 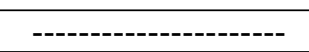 & - - \\
\hline & & Tota & Geral & 22 & & & \\
\hline
\end{tabular}




\section{ANEXO 2}

\begin{tabular}{|c|c|c|c|c|}
\hline Trabalho & Metodologia & Tema & Ferramentas & Resultados \\
\hline $\begin{array}{l}\text { Almeida } \\
\text { (2015/BA/ } \\
\text { UESB) }\end{array}$ & $\begin{array}{l}\text { Qualitativa } \\
\text { Estudo de caso } \\
\text { Produção de } \\
\text { Material }\end{array}$ & $\begin{array}{l}\text { Canções e } \\
\text { música no } \\
\text { ensino de } \\
\text { inglês }\end{array}$ & Lyrics Training & $\begin{array}{l}\text { Aplicativo auxiliou na } \\
\text { compreensão oral e } \\
\text { aquisição de vocabulário; } \\
\text { Aumento na motivação }\end{array}$ \\
\hline $\begin{array}{l}\text { Barbosa } \\
\text { (2014/BA/ } \\
\text { UESC) }\end{array}$ & $\begin{array}{l}\text { Qualitativa } \\
\text { Cunho etnográfico }\end{array}$ & $\begin{array}{l}\text { Multiletra- } \\
\text { mentos no } \\
\text { ensino de } \\
\text { inglês }\end{array}$ & $\begin{array}{l}\text { Computadores } \\
\text { com Linux } \\
\text { Buscadores } \\
\text { Redes Sociais } \\
\end{array}$ & $\begin{array}{l}\text { Formação de professores } \\
\text { precisa articular } \\
\text { letramentos do impresso } \\
\text { com letramentos digitais }\end{array}$ \\
\hline $\begin{array}{l}\text { Lemos } \\
(2017 / B A / \\
\text { UESC) }\end{array}$ & $\begin{array}{l}\text { Qualitativa } \\
\text { Pesquisa-ação } \\
\text { crítico-colaborativa }\end{array}$ & $\begin{array}{l}\text { Uso seguro } \\
\text { de redes } \\
\text { sociais; } \\
\text { Material } \\
\text { didático; } \\
\text { inglês }\end{array}$ & $\begin{array}{l}\text { WhatsApp } \\
\text { integrado com } \\
\text { outras redes }\end{array}$ & $\begin{array}{l}\text { Maior disposição } \\
\text { comunicativa; Aumento na } \\
\text { motivação; Consciência } \\
\text { sobre riscos e uso seguro } \\
\text { das redes sociais }\end{array}$ \\
\hline $\begin{array}{l}\text { Fonseca Dias } \\
\text { (2014/BA/ } \\
\text { UESC) }\end{array}$ & $\begin{array}{l}\text { Qualitativa } \\
\text { Pesquisa-ação } \\
\text { colaborativa }\end{array}$ & $\begin{array}{l}\text { Cibercultura } \\
\text { no ensino de } \\
\text { inglês }\end{array}$ & $\begin{array}{l}\text { Facebook } \\
\text { integrado com } \\
\text { outras redes }\end{array}$ & $\begin{array}{l}\text { Aumento na confiança no } \\
\text { uso de inglês; Desafio } \\
\text { escolar }\end{array}$ \\
\hline $\begin{array}{l}\text { Peixoto } \\
\text { (2015/UFBA) }\end{array}$ & $\begin{array}{l}\text { Qualitativa de } \\
\text { cunho etnográfico }\end{array}$ & $\begin{array}{l}\text { Políticas de } \\
\text { tecnologias no } \\
\text { ensino de } \\
\text { inglês }\end{array}$ & $\begin{array}{l}\text { TV Pendrive } \\
\text { (monitor } \\
\text { educacional) }\end{array}$ & $\begin{array}{l}\text { Políticas de tecnologias } \\
\text { devem-se integrar à } \\
\text { formação e à políticas de } \\
\text { educação linguística }\end{array}$ \\
\hline $\begin{array}{l}\text { Sales (2015/BA/ } \\
\text { UESB) }\end{array}$ & $\begin{array}{l}\text { Qualitativo } \\
\text { Material didático }\end{array}$ & $\begin{array}{l}\text { Estratégias de } \\
\text { leitura em } \\
\text { inglês }\end{array}$ & Google tradutor & $\begin{array}{l}\text { G tradutor pode auxiliar } \\
\text { em scanning para leitura } \\
\text { detalhada }\end{array}$ \\
\hline $\begin{array}{l}\text { Oliveira } \\
\text { (2013/BA/ } \\
\text { UESC) }\end{array}$ & $\begin{array}{l}\text { Qualitativa } \\
\text { Estudo de Caso }\end{array}$ & $\begin{array}{l}\text { Letramento } \\
\text { Digital }\end{array}$ & $\begin{array}{l}\text { TV Pendrive } \\
\text { Projetor Prolnfo } \\
\text { Linux Educacional }\end{array}$ & $\begin{array}{l}\text { É preciso fortalecer a } \\
\text { formação para uso de } \\
\text { tecnologias na EJA/Inglês }\end{array}$ \\
\hline $\begin{array}{l}\text { Santana } \\
\text { (2013/BA/ } \\
\text { UESC) }\end{array}$ & $\begin{array}{l}\text { Qualitativa } \\
\text { Análise textual } \\
\text { multimodal }\end{array}$ & $\begin{array}{l}\text { Textos em } \\
\text { ambientes } \\
\text { digitais }\end{array}$ & Blogs & $\begin{array}{l}\text { Fortalecer formação } \\
\text { professores para produção } \\
\text { de hipertextos }\end{array}$ \\
\hline $\begin{array}{l}\text { Santos } \\
(2015 / B A / \\
\text { UESC) }\end{array}$ & $\begin{array}{l}\text { Análise qualitativa } \\
\text { de Recursos } \\
\text { Eduacionais } \\
\text { Abertos (REA) }\end{array}$ & $\begin{array}{l}\text { Portais REA } \\
\text { para ensino } \\
\text { de Inglês }\end{array}$ & REA/CC & $\begin{array}{l}\text { Portais REA para ensino } \\
\text { de Inglês são limitados em } \\
\text { efetiva abertura }\end{array}$ \\
\hline $\begin{array}{l}\text { Brasil (2015/CE/ } \\
\text { UECE) }\end{array}$ & $\begin{array}{l}\text { Quali-quantitativa } \\
\text { Análise textual }\end{array}$ & $\begin{array}{l}\text { Multimodalida } \\
\text { de textual }\end{array}$ & Facebook & $\begin{array}{l}\text { Textos multimodais no } \\
\text { ensino com Facebook }\end{array}$ \\
\hline $\begin{array}{l}\text { Carvalho } \\
\text { (2016/UECE) }\end{array}$ & $\begin{array}{l}\text { Qualitativa } \\
\text { Análise textual }\end{array}$ & $\begin{array}{l}\text { Material } \\
\text { didático digital } \\
\text { Composição } \\
\text { Multimodal } \\
\text { Instrucional } \\
(\mathrm{CMI}) \\
\end{array}$ & $\begin{array}{l}\text { AVAS para ensino } \\
\text { de Inglês }\end{array}$ & $\begin{array}{l}\text { Material didático em AVAs } \\
\text { pode se fortalecer com } \\
\text { inclusão de CMI }\end{array}$ \\
\hline $\begin{array}{l}\text { Martins } \\
\text { (2015/UFC) }\end{array}$ & Quali-quantitativa & $\begin{array}{l}\text { Desenvolvime } \\
\text { nto da }\end{array}$ & $\begin{array}{l}\text { Aplicativos de } \\
\text { Pronúncia de }\end{array}$ & $\begin{array}{l}\text { Todos aplicativos } \\
\text { analisados não seguem a }\end{array}$ \\
\hline
\end{tabular}


Belo Horizonte, v. 12, n. 2, p. 117-139, mai.-ago. 2020 - ISSN 1983-3652

DOI : $10.35699 / 1983-3652.2020 .24379$

\begin{tabular}{|c|c|c|c|c|}
\hline & & $\begin{array}{l}\text { pronúncia em } \\
\text { inglês }\end{array}$ & Inglês & $\begin{array}{l}\text { abordagem comunicativa, } \\
\text { mas podem enriquecer a } \\
\text { pronúncia }\end{array}$ \\
\hline $\begin{array}{l}\text { Santos } \\
\text { (2014/UFC) }\end{array}$ & $\begin{array}{l}\text { Experimentos com } \\
\text { rastreamento } \\
\text { ocular }\end{array}$ & $\begin{array}{l}\text { Cognição na } \\
\text { leitura em } \\
\text { inglês }\end{array}$ & $\begin{array}{l}\text { Hiperlinks } \\
\text { Hipertextos }\end{array}$ & $\begin{array}{l}\text { Hiperlinks dificulta a } \\
\text { cognição na leitura em } \\
\text { inglês }\end{array}$ \\
\hline $\begin{array}{l}\text { Turolo-Silva } \\
\text { (2015/UFC) }\end{array}$ & $\begin{array}{l}\text { Qualitativa } \\
\text { complexa }\end{array}$ & $\begin{array}{l}\text { Affordances } \\
\text { em } \\
\text { EAD/Inglês }\end{array}$ & $\begin{array}{l}\text { AVA } \\
\text { Chats } \\
\text { Fóruns }\end{array}$ & $\begin{array}{l}\text { Complexidade de } \\
\text { affordances em AVAs; } \\
\text { Emergência de } \\
\text { affordances de confiança }\end{array}$ \\
\hline $\begin{array}{l}\text { Pereira } \\
\text { (2016/UFCG) }\end{array}$ & $\begin{array}{l}\text { Pesquisa-ação } \\
\text { colaborativa }\end{array}$ & $\begin{array}{l}\text { Multimodalida } \\
\text { de }\end{array}$ & Facebook & $\begin{array}{l}\text { Mais interação in inglês; } \\
\text { aumento na motivação }\end{array}$ \\
\hline $\begin{array}{l}\text { Silva } \\
\text { (2013/UFPB) }\end{array}$ & $\begin{array}{l}\text { Quali-quantitativa; } \\
\text { Pesquisa-ação } \\
\text { colaborativa }\end{array}$ & $\begin{array}{l}\text { Produção de } \\
\text { quadrinhos } \\
\text { digitais em } \\
\text { inglês }\end{array}$ & TONDOO & $\begin{array}{l}\text { Aumento na motivação e } \\
\text { criatividade; Consciência } \\
\text { na produção de textos } \\
\text { multimodais }\end{array}$ \\
\hline $\begin{array}{l}\text { Costa } \\
\text { (2013/UFPE) }\end{array}$ & $\begin{array}{l}\text { Pesquisa-ação } \\
\text { colaborativa } \\
\text { Quali-quantitativa }\end{array}$ & $\begin{array}{l}\text { Telefone } \\
\text { móvel no } \\
\text { ensino de } \\
\text { Inglês }\end{array}$ & $\begin{array}{l}\text { Telefone móvel } \\
\text { Aplicativos de } \\
\text { mensagem }\end{array}$ & $\begin{array}{l}\text { Melhoria na } \\
\text { aprendizagem; Maior } \\
\text { motivação dos alunos; } \\
\text { Flexibilidade de tempo e } \\
\text { espaço e maior } \\
\text { criatividade }\end{array}$ \\
\hline $\begin{array}{l}\text { Leandro } \\
\text { (2014/UFRN) }\end{array}$ & $\begin{array}{l}\text { Quase- } \\
\text { experimental } \\
\text { Métodos mistos } \\
\text { Quali-quanti }\end{array}$ & $\begin{array}{l}\text { Produção } \\
\text { escrita em } \\
\text { inglês }\end{array}$ & Google Docs & $\begin{array}{l}\text { Produção de textos com } \\
\text { maior densidade lexical; } \\
\text { Maior engajamento nas } \\
\text { tarefas colaborativas }\end{array}$ \\
\hline $\begin{array}{l}\text { Oliveira } \\
\text { (2014/UFRN) }\end{array}$ & $\begin{array}{l}\text { Transversal } \\
\text { Métodos mistos }\end{array}$ & $\begin{array}{l}\text { Motivação } \\
\text { Situacional } \\
\text { para aprender } \\
\text { inglês }\end{array}$ & $\begin{array}{l}\text { Lousa Digital } \\
\text { Interativa (LDI) }\end{array}$ & $\begin{array}{l}\text { Impacto pequeno da LDI } \\
\text { na motivação; } \\
\text { Motivação situacional é } \\
\text { variada ao longo de } \\
\text { tarefas e na mesma tarefa }\end{array}$ \\
\hline $\begin{array}{l}\text { Soares } \\
(2013 / \text { URN) }\end{array}$ & $\begin{array}{l}\text { Experimentos } \\
\text { Protocolos de } \\
\text { think-aloud }\end{array}$ & $\begin{array}{l}\text { Jogos digitais } \\
\text { no ensino de } \\
\text { inglês }\end{array}$ & MMORPG & $\begin{array}{l}\text { Melhoria na proficiência, } \\
\text { ortografia, leitura e escrita; } \\
\text { aprendizagem ativa; } \\
\text { negociação de sentido; } \\
\text { aumento na motivação }\end{array}$ \\
\hline $\begin{array}{l}\text { Souza } \\
(2014 / \text { URN) }\end{array}$ & $\begin{array}{l}\text { Experimentos } \\
\text { Testes de inglês } \\
\text { Questionários } \\
\text { qualitativos }\end{array}$ & $\begin{array}{l}\text { Produção oral } \\
\text { e cognição } \\
\text { (noticing) }\end{array}$ & Voicethread & $\begin{array}{l}\text { Ferramenta apontou } \\
\text { correlação positiva entre } \\
\text { produção oral e noticing } \\
\text { Reação positiva a } \\
\text { experiência }\end{array}$ \\
\hline $\begin{array}{l}\text { Uchôa } \\
\text { (2014/UFRN) }\end{array}$ & Pesquisa narrativa & $\begin{array}{l}\text { Didatização } \\
\text { de gêneros } \\
\text { orais em } \\
\text { inglês }\end{array}$ & Podcasts & $\begin{array}{l}\text { Progressão gradual na } \\
\text { implantação de } \\
\text { tecnologias na formação } \\
\text { inicial } \\
\text { Estratégias coerentes com } \\
\text { demandas locais }\end{array}$ \\
\hline
\end{tabular}

